\title{
Dos lingüistas nicaragüenses $e$ investigadoras del CILL autoras del Diccionario de Centroamericanismos (DICA)
}

(C) UNAN-Managua Recibido: mayo 2017 Aprobado: junio 2017

\section{Two Nicaraguan linguists and researchers from the CILL authors of the Central American Dictionary (DICA)}

El Diccionario de Centroamericanismo (DICA) es una obra lexicográfica que reúne gran parte del léxico (palabras) utilizado por seis países centroamericanos (Guatemala, El Salvador, Honduras, Nicaragua, Costa Rica y Panamá). La principal fuente de obtención del vocabulario que contiene esta obra lexicográfica se tomó del léxico recopilado en los Atlas lingüísticos de América Central, publicados hasta la fecha. La confección de este diccionario inició en el 2012, por iniciativa de las profesoras María Auxiliadora Rosales Solís, y Zobeyda Catalina Zamora Úbeda, docentes e investigadoras de la UNAN, Managua.

En el prólogo, Francis Mendoza, lexicógrafa y catedrática nicaragüense, destaca que esta obra cumple con dos criterios esenciales para la confección de un diccionario: en primer lugar, presenta un registro léxico amplio y en segundo orden, los lemas están claramente definidos. Otros aspectos que la lingüista resalta es el análisis contrastivo, es decir que se compararon los términos recopilados en Diccionario de la lengua española (2014) con el fin de excluir los que son de uso común en el español hablado tanto en España como en América.

Para Miguel A. Quesada, destacado dialectólogo y coordinador de múltiples estudios sobre el español de América Central, "la publicación de este diccionario es histórica, pues es un avance en la lexicografía del español centroamericano, ya que desde 1965 no se veía un trabajo científico similar".

Según las autoras, el DICA es un diccionario de uso porque no realiza ninguna valoración social del vocabulario ni presenta recomendaciones o preferencias fonéticas por una expresión; define palabras presentes en el habla cotidiana propias de la región centroamericana que corresponden a distintos campos socioculturales: creencias, mitos, juegos, bailes populares, alimentación, vestimenta; calificativos para denominar el cuerpo humano; frases para alejar el infortunio, la desgracia y atraer la bienaventuranza, etc. Es decir, agrupa, siguiendo criterios lingüísticos, lexicográficos y antropológicos, los elementos que conforman parte de la identidad cultural del español centroamericano.

EI DICA es una obra lexicográfica que se debe agregar a la lista de los estudios de terminología centroamericana, reúne las marcas diatópicas (de países), entradas (palabras) y acepciones (definiciones) que suman un total de 34,376, de las cuales 751 son vocablos que se comparten en toda la región: 5,007 corresponden a Guatemala; 7,667 a El Salvador; 5,857 a Honduras; 6429 a Nicaragua; 4672 a Costa Rica y 3993 a Panamá. 


\section{Una probadita de lo que contiene el DICA}

fachento, -a. ${ }^{\circ}$ adj. Ho, El Salv., Ni, CR. Relativo a persona, engreída, jactanciosa. Como puede notarse en las marcas de los países la palabra "fachento" es usada en Honduras, El Salvador, Nicaragua y Costa Rica.

jodido, -a. ${ }^{\circ} \mathrm{m}$. y f. ${ }^{\circ} \mathrm{Ni}$. Relativo a alguien, que está enfermo. $\| 2$. sust./adj. ${ }^{\circ} \mathrm{El} \mathrm{Salv}$., Ni, CR. Persona, que molesta mucho.

chucho. ${ }^{\circ} \mathrm{m} .{ }^{\circ} \mathrm{Gu}$. Tuerca para fijar la rueda de un vehículo al tambor. $\| 2 .{ }^{\circ} \mathrm{Gu}$. Cuña para calzar las ruedas de un vehículo. $\| 3 .^{\circ} E$ I Salv. Perro.

chucanada. ${ }^{\circ} \mathrm{f} .{ }^{\circ} \mathrm{Gu}, \mathrm{Ho}$, El Salv. Broma jocosa.

chueco, -a. adj. AC. Relativo a cosa, que está torcida.

chupada. f. Pa. Hábito de tomar bebidas alcohólicas. ||2. Pa. Fiesta donde abunda el alcohol.

En este Diccionario se define tanto las palabras que son de uso exclusivo en un país como aquellas que se comparten, por ejemplo, la palabra "chueco" utilizada en toda América Central.

Este diccionario es la muestra de toda la riqueza léxica que existe en el español centroamericano. Estamos seguros de que el DICA servirá de consulta a estudiantes y maestros de lengua española, tanto de lengua materna como de segunda lengua, a profesionales de la comunicación y a toda persona interesada en el acervo léxico del español centroamericano. 